\title{
Evaluate the Impact of Cold Wave on Face Slab Cracking Using Fuzzy Finite Element Method
}

\author{
Dongjian Zheng, Lin Cheng, and Yanxin Xu \\ College of Water Conservancy and Hydropower Engineering, Hohai University, Nanjing, Jiangsu 210098, China \\ Correspondence should be addressed to Lin Cheng; wanmu2381@163.com
}

Received 6 November 2012; Revised 7 February 2013; Accepted 7 February 2013

Academic Editor: Valentina E. Balas

Copyright (c) 2013 Dongjian Zheng et al. This is an open access article distributed under the Creative Commons Attribution License, which permits unrestricted use, distribution, and reproduction in any medium, provided the original work is properly cited.

\begin{abstract}
We use fuzzy finite element method (FEM) to analyze the impact of cold wave on face slab cracking of a concrete-faced rockfill dam (CFRD). The static response of dam and the temperature field of face slab are calculated using deterministic FEM since some observed and test data can be obtained. Some parameters of Goodman contact element between face slabs and cushion material are selected as fuzzy variables, and the fuzzy FEM is used to calculate fuzzy stress of face slab. The fuzzy FEM is implemented using vertex method based on the extension principle. Through the analysis of two selected calculation cases of cold wave, it is shown that the calculated cracking direction and cracking zone caused by thermal stress are similar to those of the observed cracks. This proves that the cold wave that caused swift air temperature drop is an important reason for the cracking of face slab. According to these analysis results, some cracking prevention measures are then proposed.
\end{abstract}

\section{Introduction}

Recently, the method of finding reasonable and effective structural damage prevention and treatment measures with the help of finite element method (FEM) has been widely applied to hydraulic engineering. The implementation of FEM is becoming more and more convenient with the emergence of some commercial software. However, for a practical engineering problem, there are maybe some vague and imprecise information in the geometry, material, boundary condition, and load of structure when the FEM is implemented. One way to reduce these ambiguities is using the inversion analysis method proposed by Kavanagh and Clough [1] when enough monitoring data of structural response (displacement, temperature and stress, etc.) can be obtained. The fuzzy FEM proposed by Rao and Sawyer [2] is another way to solve this problem. The fuzzy FEM takes the imprecise quantities as fuzzy variables and then calculates the corresponding fuzzy structural response. For a structural response, while the deterministic FEM provides us with a deterministic value, the fuzzy FEM provides us with some different values with their possibility distribution. This makes the analysis result of fuzzy FEM more meaningful than that of traditional methods, and many applications of this method in engineering can be found in [2-4].

In this paper, a practical engineering problem is solved using the deterministic and fuzzy FEM. This engineering is a high concrete-faced rockfill dam (CFRD). Some cracks were found on the concrete face slab during normal operation period. For a CFRD, the concrete faced slab is its main seepage prevention structure, and its operation state of is closely related to the normal operation and the benefits playing of the whole project. If there are some cracks on the face slab or the transverse joints of between face slabs are improperly handled, it may cause a serious engineering accident, or even a disaster. For example, one of the most important reasons for the catastrophic dam failure of the Gouhou [5] CFRD is that the sealing between construction joints was not installed properly. Therefore, enough attention should be paid to these cracks on the face slab of Gongboxia CFRD.

Generally, cracks on face slab are often found during construction stage of CFRD because of the hydration heat of concrete and the local strong constraints at the bottom of face slab. Therefore, most current research on face slab cracking problem is limited to the construction stage. For 
example, Wang et al. [6] calculated the thermal stress of face slabs under cold wave attack in construction stage. Zhou et al. [7] used the face slab submodel to find the reason for face slab cracking during construction stage. Arici [8], however, studied the cracking behavior of the face slab of a CFRD over its life cycle, including construction, impounding, longterm deformation, and earthquake loading. Nevertheless, he did not consider the thermal stress. In addition, in the above studies on the cracking behavior of face slab, the deterministic FEM is adopted and the uncertainty of material parameters is not taken into account, which may make the analysis results have great difference with practical situation.

For the Gongboxia CFRD, cracks on face slab are found during the normal operation period. The characteristic of these cracks and the climatic and geographical features of this project indicate that the cold wave that caused sharp temperature drop in winter and spring may be an important reason for these cracks. In order to confirm this assumption, the impact of cold wave on face slabs cracking is studied. The research is implemented by performing a three-step finite element analysis: calculation of the initial stress using a finite element (FE) model of the CFRD, calculation of the temperature filed and thermal stress using face slab submodel. In order to make the analysis result more reliable, in our following research, the load of construction stage, impounding stage, cold wave that caused thermal stress, and the uncertainties of material parameters are all taken into account. The monitoring data of dam settlement and slab temperature are used to reduce the fuzzy information of analysis to obtain some deterministic results. Some parameters of contact element are taken as fuzzy variables, and the fuzzy stress of face slab is calculated using fuzzy FEM. Based on these analysis results, some conclusions are drawn, and some suggestions to prevent the further cracking of face slab are proposed in the final of this work.

\section{Gongboxia CFRD and Observation Results of Cracks}

The Gongboxia CFRD is located in the Yellow river of China. As is shown in Figure 1, this project is mainly composed of three parts: a CFRD, a waterpower generation system, and discharge structures. During normal operation period, the water level of the reservoir is about $2002.0 \mathrm{~m}$. The maximum cross-section of the CFRD and the material zoning of dam is shown Figure 2.

The dam site is located at the Qinghai-Tibet plateau of China. In dam site area, the east latitude is about $102^{\circ}$, and the north longitude is about $36^{\circ}$. The elevation ranges from $1800 \mathrm{~m}$ to $2000 \mathrm{~m}$. The difference of air temperatures between day and night is usually very big, and the winter is very long. The maximum temperature drop in a day is $14.2^{\circ} \mathrm{C}$, and cold wave occurs 14 times annually in average. In this work, cold wave is defined as a weather process during which the air temperature drop is more than $10^{\circ} \mathrm{C}$ in a day, and the minimum air temperature is below $5^{\circ} \mathrm{C}$. Since the thermal conductivity of concrete material is poor, when the temperature of face slab upper surface has dropped sharply

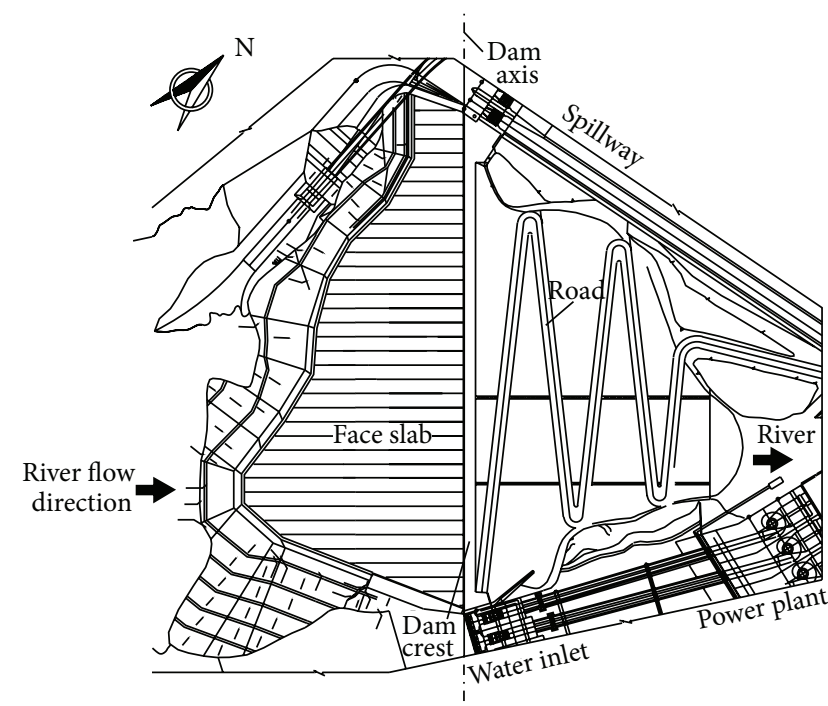

FIGURE 1: Plane layout of the project.

due to the swift drop of air temperature, the temperature of bottom surface usually has not been changed at all. This may result in great temperature gradient and great tensile stress as a result [9].

CFRDs are very complicated hydraulic structures when considering the contact relationship between rockfill material, face slabs and toe slabs. Concrete face slab is the main seepage prevention structure of a CFRD. However, the face slab is also the weakest part of dam, since it is very thin and some joints filled with sealing materials are set between different face slabs to reduce the deformation. In order to monitore the safety of the face slab, some instruments, such as joint meters, thermal meters, and strain meters, are installed on it. Figure 3 shows the contact relationship between different parts of Gongboxia CFRD and some instruments installed on the face slab.

At present, 135 cracks have been found on the face slabs of which 129 are horizontal cracks and 6 are transverse cracks. Figure 4(a) shows the statistics of the number of cracks on each face slab. From the right side to the left side of dam (in hydraulic engineering, if you stand facing the river flow direction, then the right side refers to the right hand side), face slabs are numbered from 1 to 38 . Face slabs numbered from 8 to 11 are located on the dam sections of riverbed, and the other face slabs locate on the dam sections of riverbank. We can see from this figure that the number of cracks on face slabs near the riverbank is greater than that on the face slab near the river center. The distribution of cracks along the dam axis is symmetric. Most cracks are above the reservoir water level (elevation: $2002.0 \mathrm{~m}$ ), and $22 \mathrm{cracks}$ extend to the elevation below the water level. According to underwater exploration by diver, cracks extend to the elevation of $1996.5 \mathrm{~m}$ in the deepest. The cracks are wider at the top, and the width is between $0.02 \mathrm{~mm}$ and $0.45 \mathrm{~mm}$. According to the core-drilling results of a face slab, see Figure 4(b), the maximum crack depth is greater than the core-drilling sample length of $24 \mathrm{~cm}$. The total number of cracks on face 




FIGURE 2: The maximum cross-section of the CFRD and the material zoning.

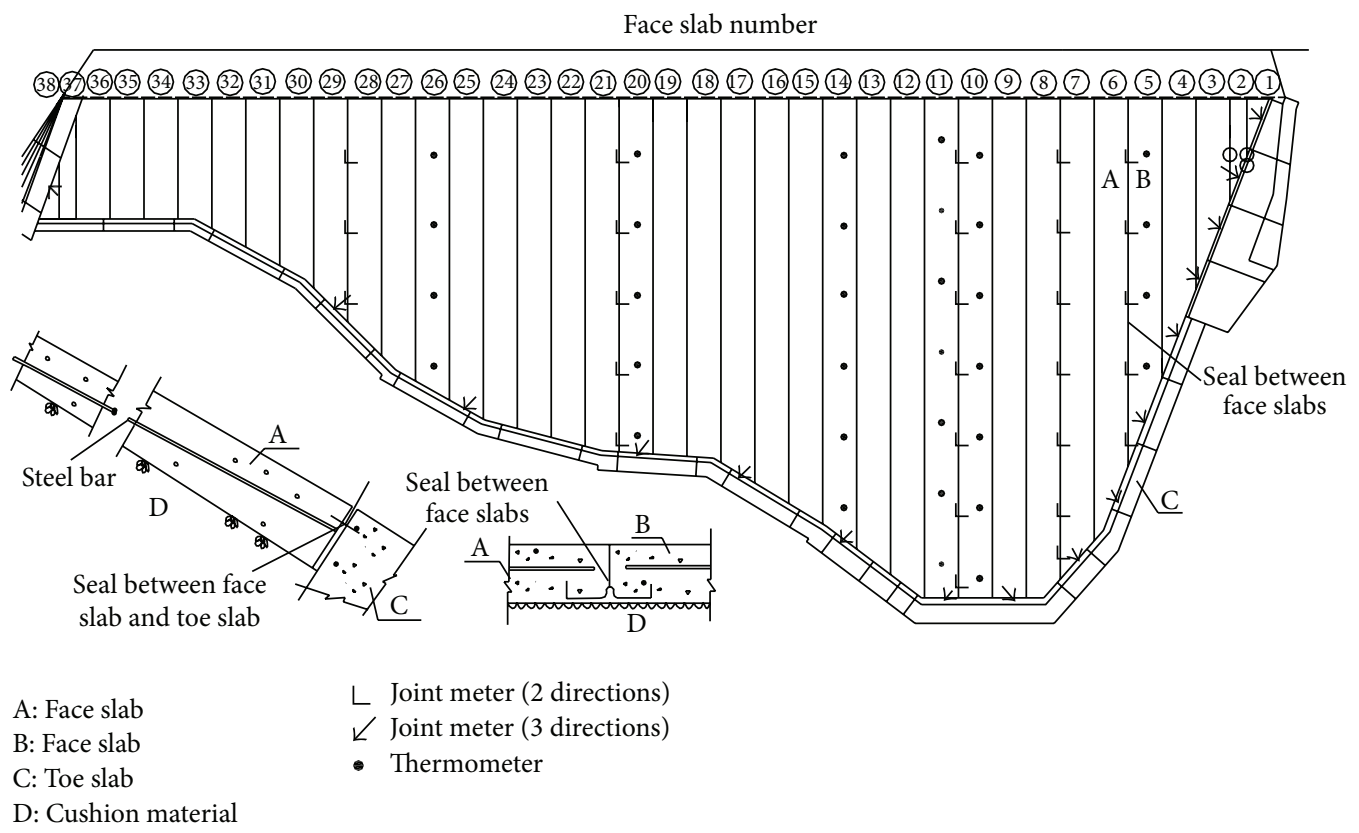

FIGURE 3: Observation instruments on face slabs and the contact relationships between different parts of CFRD.

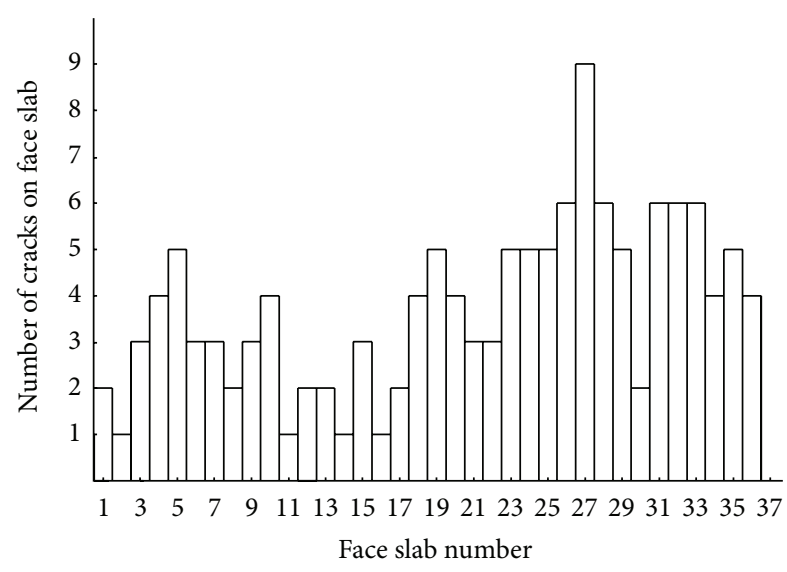

(a)

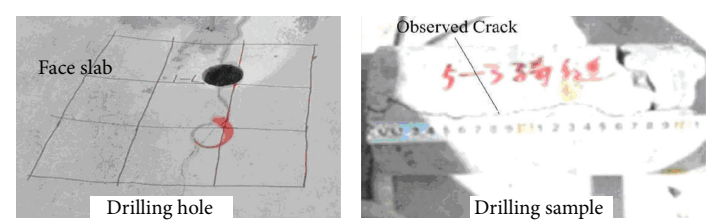

(b)

Figure 4: (a) The statistics of cracks on face slabs and (b) a core-drilling sample of concrete face slab with crack. 
slabs is increasing year by year, and the number of cracks in winter is greater than in summer, which is consistent with the general perception that the shrink of concrete will cause cracks.

\section{Fuzzy FEM}

The mechanical properties of CFRD material are usually very complex and there, is always some uncertain information in the constitutive model of it. Some researchers $[10,11]$ have tried to use nondeterministic FEM method to analyze the stress and deformation of CFRDs. In our work, in order to evaluate the impact of cold wave on face slab cracking, the fuzzy FEM method is adopted. In the following section, we will introduce some basic principles of this method.

For structure static problem, the FE equilibrium equation can be given by

$$
\mathbf{K U}=\mathbf{P},
$$

in which $\mathbf{K}, \mathbf{U}$, and $\mathbf{P}$ are the stiffness matrix, displacement vector, and load vector of structure, respectively.

When only some material parameters are considered as fuzzy, the fuzzy finite element equilibrium equation is as follows [12]:

$$
\overline{\mathbf{K}} \overline{\mathbf{U}}=\mathbf{P}
$$

where $\overline{\mathbf{K}}$ and $\overline{\mathbf{U}}$ are the fuzzy stiffness matrix and fuzzy displacement vector of structure, respectively.

The fuzzy response of structure can be calculated using two key steps: (1) selection and modeling of fuzzy variables; (2) calculation of fuzzy response based on extension principle. The fuzzy FEM begins with selecting some fuzzy variables of structural geometry, material, boundary condition, and load. Then, the membership functions of these fuzzy variables are determined. The membership function provides a possibility distribution for each fuzzy variable. Some methods to determine the membership functions and some commonly used membership functions can be found in [13]. Triangular membership function, as is shown in Figure 5, is adopted in this study. The corresponding membership of the value $e$ is 1.0 , which means that $e$ is belonging to the fuzzy set determinately.

The fuzzy response of structure can be calculated based on the extension principle. This principle relates the possibility distribution of the input fuzzy quantities of a function to the possibility distributions of the output fuzzy quantity of the function. For a fuzzy variable $x_{i}\left(-\infty<x_{i}<\infty, 1<\right.$ $I<r)$, the corresponding membership is $\mu_{A_{i}}\left(x_{i}\right)$. If there is a mapping from input $\mathbf{x}=\left(x_{1}, \ldots, x_{r}\right)$ to output $y=$ $f(\mathbf{x})$, then the membership of output variable $\mu_{B}(y)$ can be calculated as follows:

$$
\mu_{B}(y)= \begin{cases}\sup \min _{\mathbf{x}=f^{-1}(y)}\left(\mu_{\widetilde{A}_{1}}\left(x_{1}\right) \ldots, \mu_{\widetilde{A}_{r}}\left(x_{r}\right)\right), & f^{-1}(\mathbf{x}) \neq 0 \\ 0, & \text { otherwise }\end{cases}
$$

in which the supremum is an operator which gives the least upper bound. The principle can be interpreted as follows.

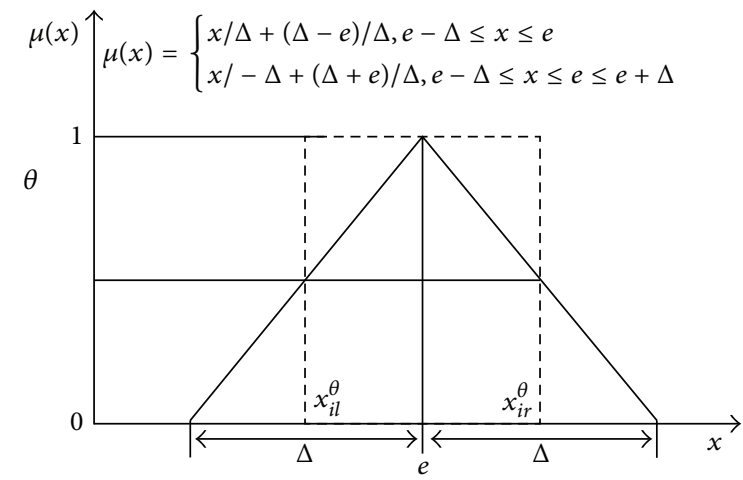

FIgURE 5: Triangular membership function.

For a possible output $y=y_{0}$, there are may some different combinations of fuzzy variables which make $y_{0}=f(\mathbf{x})$, namely, the mapping $f(\cdot)$ is a many-to-one mapping. Then, the possibility of output $f(\mathbf{x})=y_{0}$ is equal to the maximum possibility of all the combinations. The possibility of each combination is equal to the minimum possibility value of all the fuzzy variables in this combination.

Although some new methods to implement fuzzy FEM, such as transformation method [14], adaptive response surface method [15], and sparse grid metamodel method [16], have been proposed, the vertex method, which was introduced by Dong and Shah [17], is used here, since the implementation of this method is simple and the number of fuzzy variables selected by us is small. The vertex method is based on the assumption that the extremes of the solution are a combination of the extremes of the interval parameters. For the fuzzy FEM, the mapping $f(\cdot)$ of above expression is the FE model which projects the fuzzy material variables into the fuzzy response of structure. Based on the extension principle, the fuzzy response of structure can be calculated using the following steps.

Step 1. For each fuzzy variable $x_{i}(i=1,2, \ldots, r)$, use the $\theta$ level method to represent it and obtain the $\theta$ level cut set $\left[x_{i l}^{\theta}, x_{i r}^{\theta}\right]$. As is shown in Figure 3, $x_{i l}^{\theta}$ and $x_{i r}^{\theta}$ are the left (lower) and right (upper) bound, of the set, and $\mu\left(x_{i}=x_{i l}^{\lambda}\right)=\mu\left(x_{i}=\right.$ $\left.x_{i r}^{\lambda}\right)=\theta$.

Step 2. At level $\theta$, generate $2^{r}$ binary combinations of the left and right bound values of all the $\theta$ level cut sets of the $r$ fuzzy variables.

Step 3. For each of the $2^{r}$ combinations, use FEM to calculate the corresponding structure response.

Step 4. Select the maximum and minimum values of all the calculated response as the lower and upper bounds of the $\theta$ level cut set of fuzzy response.

Step 5. Select $l$ different levels $\theta_{j}(j=1,2, \ldots, l)$, and repeat the process of Steps 1-4 to calculate the fuzzy response of structure at $l$ different levels. Then, the possibility distribution of fuzzy response can be obtained. 


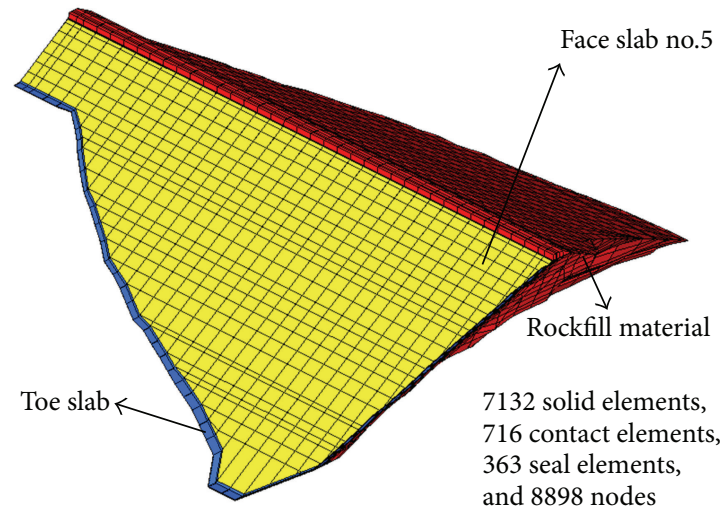

(a)

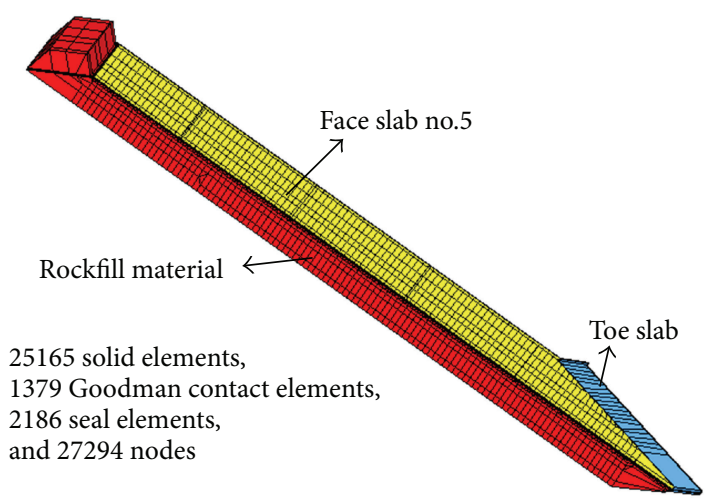

(b)

Figure 6: (a) FE model of the CFRD and (b) the FE submodel of face slab no. 5.

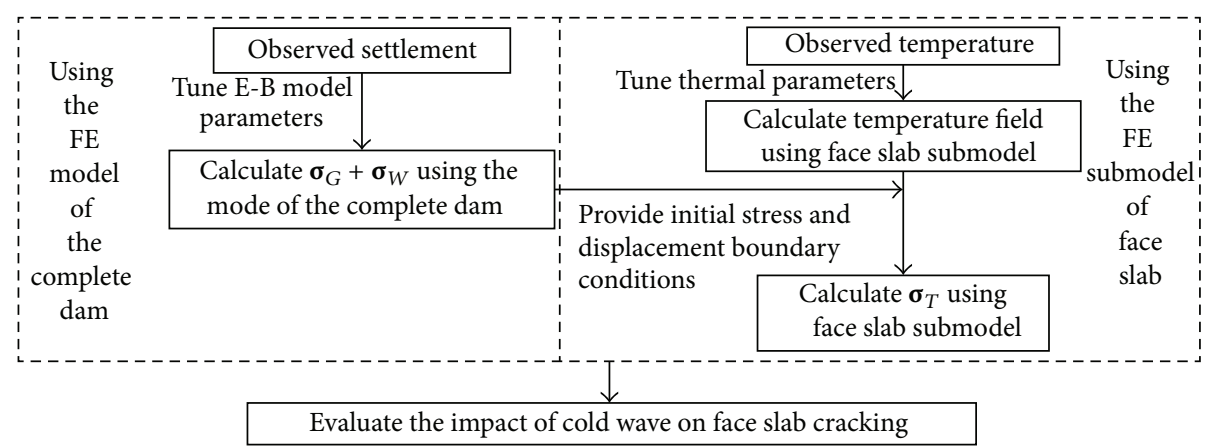

FIGURE 7: The flow chart of analysis.

\section{Evaluate the Impact of Cold Wave on Face Slab Cracking}

4.1. Construct Numerical Model. Similar to the traditional FEM, for the practical implementation of fuzzy FEM, the FE model is also needed. In order to simulate the construction and impounding processes of the Gongboxia CFRD, it is necessary to construct a $3 \mathrm{D}$ FE model of the complete dam. The mesh of this 3D model should not be too intense to save the calculation time. During the operation period, the temperature field of the CFRD is quasisteady indeed, which means that only the concrete face slab and the outer surface of dam will be affected by the air temperature. Therefore, the thermal stress calculation can be implemented in the local area around face slab. Therefore, we use a face slab submodel [7] to analyze the temperature field and thermal stress of face slab. Since most found cracks are on the face slabs near riverbank, only a typical face slab, face slab no. 5 near riverbank is analyzed in this work. As is shown in Figure 4(a), five cracks have been found on it. In addition, some instruments have been installed on the face slab (see Figure 3), which will facilitate our analysis in the following. The FE model of the complete CFRD and the submodel of face slab no. 5 are shown in Figure 6.

4.2. The Analysis Process. For each face slab, the total stress is composed of three parts: gravity caused stress $\sigma_{G}$, water pressure caused stress $\boldsymbol{\sigma}_{W}$, and cold wave caused stress $\boldsymbol{\sigma}_{T}:$

$$
\boldsymbol{\sigma}=\boldsymbol{\sigma}_{\mathrm{G}}+\boldsymbol{\sigma}_{W}+\boldsymbol{\sigma}_{T}
$$

Therefore, the analysis consists of three steps, and flow chart of it is shown in Figure 7.

Step 1. Use the FE model of the complete CFRD to simulate the construction and impounding process and calculate the stress $\sigma_{G}+\sigma_{W}$.

Step 2. Use the submodel of a face slab to calculate its quasistationary temperature field.

Step 3. Take the calculated stress $\boldsymbol{\sigma}_{G}+\boldsymbol{\sigma}_{W}$ from Step 1 as initial stress. The displacement of nodes on the boundary of submodel is constrained, since the sphere influenced by cold wave is limited to the local area around face slab. Then, based on the calculated temperature field from Step 2 and the reference temperature field of face slab, the thermal stress of the face slab is calculated. With the calculated thermal stress, we can evaluate the impact of cold wave on face slab cracking.

In this work, we consider the geometry, boundary condition, and load of structure as deterministic. Using the observed settlement of the CFRD, the material parameters of rockfill material have been identified through inversion 


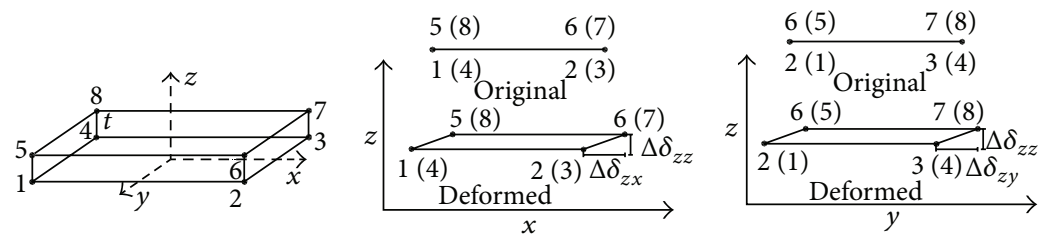

FIGURE 8: Goodman contact element.

analysis in [18] and in our previous work [19]. Therefore, these parameters of rockfill material can be seemed as deterministic. The analysis of temperature field is taken as deterministic too, since the observed temperature from thermometers on face slab no. 5 (see Figure 3) can be used to tune the thermal parameters. The commonly used sealing materials, [20] in CFRD are copper and plastic. Similar to the concrete material, the testing techniques of these materials are well developed, and the tested material parameters have a good accuracy. Therefore, the material parameters of concrete and sealing materials are taken as deterministic too.

4.3. Goodman Contact Element with Fuzzy Parameters. As is shown in Figure 8, the so-called Goodman element [21] is usually adopted to simulate the contact between face slabs and cushion material. For the Goodman element, the relationship between force and relative displacement can be given by [22]

$$
\left\{\begin{array}{l}
\Delta F_{z x} \\
\Delta F_{z y} \\
\Delta F_{z z}
\end{array}\right\}=\left\{\begin{array}{ccc}
k_{z x} & 0 & 0 \\
0 & k_{z y} & 0 \\
0 & 0 & k_{z z}
\end{array}\right\}\left\{\begin{array}{l}
\Delta \delta_{z x} \\
\Delta \delta_{z y} \\
\Delta \delta_{z z}
\end{array}\right\}
$$

where $\Delta \delta_{z x}$ and $\Delta \delta_{z y}$ are relative tangential displacements, and $\Delta \delta_{z z}$ is the relative normal displacement of two contacting surfaces. $\Delta F_{z x}$ and $\Delta F_{z y}$ are the tangential force, and $\Delta \delta_{z z}$ is the normal force. Usually, the normal stiffness $k_{z z}$ is set as a big value, for example, $10^{11} \mathrm{~Pa}$, under compressive stress and a small value, for example, $10^{4} \mathrm{~Pa}$, under tensile stress. The tangential stiffness of Goodman element is given by

$$
k_{z x}=k_{1} \gamma_{w}\left(\frac{\sigma_{z}}{p_{a}}\right)^{n}\left[\frac{1-R_{f} \tau_{z x}}{\left(\sigma_{z} \tan \delta\right)}\right]^{2},
$$

where $\gamma_{w}$ is the bulk density of water, $\sigma_{n}$ is normal stress of contact surface, and $\tau_{z y}$ is the tangential stress. Four parameters $k_{1}, n, R_{f}$, and $\delta$ need to be determined by experiment. However, there are no experimental data for the above four parameters in this engineering. In addition, while the contact stiffness between face slab and cushion material has great influence on the stress of face slab, the testing technology for these parameters is not satisfactory currently. These parameters may have considerable difference in different projects. Therefore, the four parameters $k_{1}, n$, $R_{f}$, and $\delta$ are taken as fuzzy variables in this study. Some parameters of their triangular membership functions are given in Table 1.
TABLE 1: Fuzzy variables and the parameters corresponding to the triangular membership function.

\begin{tabular}{lcccc}
\hline Parameters & $\delta\left(^{\circ}\right)$ & $k_{1}$ & $R_{f}$ & $n$ \\
\hline$e$ & 32 & 21000 & 0.8 & 1.25 \\
$\Delta$ & 10 & 10000 & 0.1 & 0.15 \\
\hline
\end{tabular}

4.4. Constitutive Model for Concrete Material and Rockfill Material. The elastic constitutive model is used for concrete material of face slabs and toe slabs. The elastic modulus is 2.2 $\times 10^{10} \mathrm{~Pa}$, and Poisson's ratio is 0.167 . Since the property of the rockfill material of CFRD is essentially nonlinear, a type of nonlinear model, E-B model [23] is used in this paper to express this nonlinear property. Generally, the E-B model is expressed by an elastic modulus $E_{t}$ and a bulk modulus $B_{t}$. They are given by

$$
E_{t}= \begin{cases}\text { loading : } & K p_{a}\left(1-R_{f} S\right)^{2}\left(\frac{\sigma_{3}}{p_{a}}\right)^{n}, \\ \text { unloading or reloading : } & K_{u r} p_{a}\left(\frac{\sigma_{3}}{p_{a}}\right)^{n}, \\ B_{t}=K_{b} p_{a}\left(\frac{\sigma_{3}}{p_{a}}\right)^{m},\end{cases}
$$

where the shear stress ratio, or stress level $S=\left(\sigma_{1}-\right.$ $\left.\sigma_{3}\right) /\left(\sigma_{1}-\sigma_{3}\right)_{f} ;\left(\sigma_{1}-\sigma_{3}\right)_{f}=(2 c \cos \varphi+2 \sigma 3 \sin \varphi) /(1-\sin \varphi)$ is the deviator stress when the tested material fails; $\varphi$ is the internal friction angle; $p_{a}$ is the air pressure; and $\sigma_{1}$ and $\sigma_{3}$ are the maximum and the minimum principle stresses, respectively. Parameters $c, \varphi, \Delta \varphi, K, K_{u r}, n, R_{f}, K_{b}$, and $m$ in the above equations can be determined by triaxial tests on the rock-fill material. In this work, the identified result in [19] is used.

Elastic matrix $\mathbf{D}$ can be calculated using the elastic modulus $E_{t}$ and the bulk modulus $B_{t}$ as follows:

$$
\mathbf{D}=\frac{3 B_{t}}{9 B_{t}-E_{t}}\left[\begin{array}{cccccc}
3 B_{t}+E_{t} & 3 B_{t}-E_{t} & 3 B_{t}-E_{t} & 0 & 0 & 0 \\
3 B_{t}-E_{t} & 3 B_{t}+E_{t} & 3 B_{t}-E_{t} & 0 & 0 & 0 \\
3 B_{t}-E_{t} & 3 B_{t}-E_{t} & 3 B_{t}+E_{t} & 0 & 0 & 0 \\
0 & 0 & 0 & E_{t} & 0 & 0 \\
0 & 0 & 0 & 0 & E_{t} & 0 \\
0 & 0 & 0 & 0 & 0 & E_{t}
\end{array}\right] .
$$


TABLE 2: Thermal parameters.

\begin{tabular}{lccccc}
\hline Material & $\gamma\left(\mathrm{kg} / \mathrm{m}^{3}\right)$ & $c\left(\mathrm{~kJ} /\left(\mathrm{kg} \cdot{ }^{\circ} \mathrm{C}\right)\right)$ & $\lambda\left(\mathrm{kJ} /\left(\mathrm{m} \cdot \mathrm{d} \cdot{ }^{\circ} \mathrm{C}\right)\right)$ & $\beta\left(\mathrm{kJ} /\left(\mathrm{m}^{2} \cdot \mathrm{d} \cdot{ }^{\circ} \mathrm{C}\right)\right)$ & 847.92 \\
\hline Cushion & 2150 & 0.88 & 127.20 & 988.80 & 0.30 \\
Transition & 2130 & 0.88 & 148.32 & 707.28 & 0.30 \\
Rock-fill & 2080 & 0.74 & 106.08 & 1272.00 & 0.85 \\
Concrete & 2395 & 0.98 & 211.92 & 1272.00 \\
Base rock & 2450 & 1.05 & 190.80 & 10.00 \\
\hline
\end{tabular}

After the elastic matrix $\mathbf{D}$ has been calculated, the element stiffness matrix $\mathbf{k}^{e}$ of structure is constructed as follows:

$$
\mathbf{k}^{e}=\int_{V^{e}} \mathbf{B}^{T} \mathbf{D} \mathbf{B} d v
$$

where $\mathbf{B}$ is the strain transformation matrix. The overall stiffness matrix $\mathbf{K}$ in (1) can be constructed using this element stiffness matrix $\mathbf{k}^{e}$.

4.5. Calculate Temperature Field and Thermal Stress. The quasisteady temperature field $T=T(x, y, z, t)$ should satisfy the following equation $[24,25]$ :

$$
\frac{\partial T}{\partial t}=a\left(\frac{\partial^{2} T}{\partial x^{2}}+\frac{\partial^{2} T}{\partial y^{2}}+\frac{\partial^{2} T}{\partial z^{2}}\right)
$$

in which $a$ is thermal diffusivity. The calculation of temperature field is under the initial state $T=T\left(x, y, z, t_{0}\right)$ and three types of boundary conditions. In this work, the initial temperature of submodel is set as annual average temperature $8.5^{\circ} \mathrm{C}$. The thermal boundary conditions of face slab submodel are shown in Figure 9. In the figure, $T_{a}$ is air temperature, and $q$ is heat flux. The boundary temperature of base rock is fixed at the average ground temperature $T_{g}=$ $11.5^{\circ} \mathrm{C}$. The temperature of face slab upper surface immersed in water is set the same as measured water temperature $T_{w}$. They both belong to the fixed temperature boundary $\Gamma 1$. Thermal radiation caused by sunshine belongs to the thermal boundary condition $\Gamma 2$ and the thermal flux $q=1.78 \times$ $10^{4} \mathrm{~kJ} /\left(\mathrm{m}^{2} \cdot \mathrm{d}\right)$. Ignore the flux exchange between adjacent face slabs, and the flux is assumed to flow in the direction perpendicular to the face slab. The disconnected position between submodel and dam is deemed as adiabatic. The thermal boundary conditions of face slab above the water level and the dam surface are both taken as the surface exchange boundary Г3. Some thermal parameters of different material of dam are shown in Table 2. These parameters include thermal conductivity $\lambda$, surface heat transfer coefficients $\beta$, mass density $\gamma$, coefficient of linear expansion $\alpha$, and specific heat $c$.

Two typical cold wave processes were studied in this work:

(1) a typical cold wave occurred in spring with the maximum temperature drop $14.6^{\circ} \mathrm{C}$ in a day,

(2) a cold wave occurred in the last ten days of January 2008 with the lowest temperature $-14.3^{\circ} \mathrm{C}$.

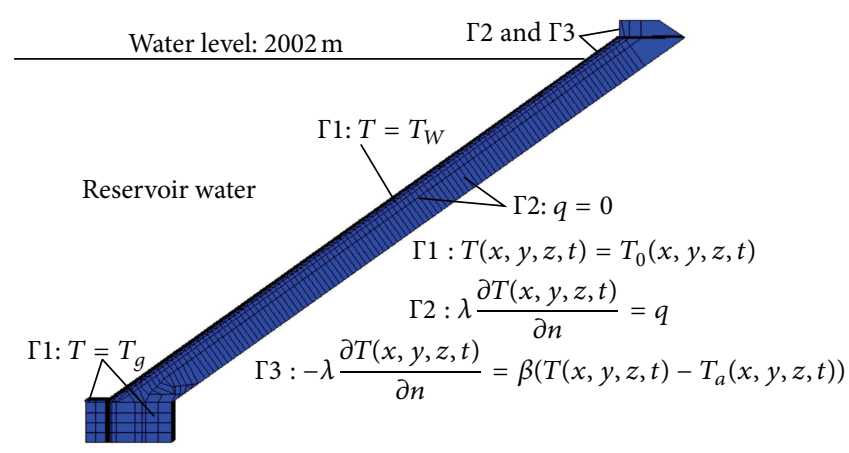

FIGURE 9: Thermal boundary conditions of submodel.

The initial strain method is adopted to calculate the thermal stress, which takes the temperature strain as initial strain and then converts it into the equivalent nodal loads. Then, this problem can be solved using common FEM program by adding the thermal caused nodal load to other kind of loads

$$
\mathbf{F}^{e}=\mathbf{k}^{e} \boldsymbol{\delta}^{e}+\int_{V^{e}} \mathbf{B}^{T} \mathbf{D} \boldsymbol{\varepsilon}_{0} d v,
$$

where $\mathbf{k}^{e}, \mathbf{F}^{e}$, and $\boldsymbol{\delta}^{e}$ are the stiffness matrix, load matrix and displacement matrix of element, respectively; $\mathbf{B}$ is shape function matrix, and $\mathbf{D}$ is elastic matrix.

For the above equation, the second item of the right side is the equivalent nodal load, and the thermal strain $\boldsymbol{\varepsilon}_{0}$ is given by

$$
\boldsymbol{\varepsilon}_{0}=\alpha T\left[\begin{array}{llllll}
1 & 1 & 1 & 0 & 0 & 0
\end{array}\right]^{T} .
$$

The initial tangential modulus $E_{t}$ and bulk modulus $B_{t}$ of rockfill material and the initial stiffness of seal element can be obtained from Step 1 shown in Section 4.2.

\section{Analysis Results}

For $l=4$ different levels, $\theta=0,0.45,0.75$, and 1.0, the fuzzy response of structure is calculated. For each combination of fuzzy variables, the commercial FEM software MSC.Marc [26] is used to calculate the structure response. The computation timse (CPU time on a machine with a Dual Core $1.80 \mathrm{GHz} \mathrm{CPU}$ and the memory size of $2 \mathrm{~GB}$ ) for the three steps mentioned in the Section 4.2 of this paper are 687 minutes, 18 minutes, and 961 minutes, respectively, and the total computation time is 1666 minutes. 


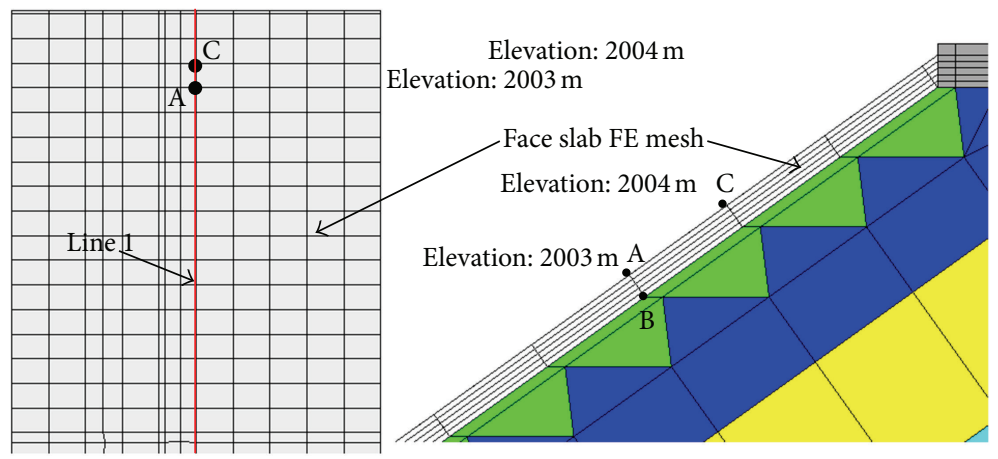

FIGURE 10: Some typical nodes of face slab FE mesh.

TABLE 3: Calculated and observed cracking range of face slab no. 5.

\begin{tabular}{lccccc}
\hline & Case 1 & \multicolumn{2}{c}{ Case 2 } & \multicolumn{2}{c}{ Observed } \\
Elevation $(\mathrm{m})$ & Depth $(\mathrm{cm})$ & Elevation $(\mathrm{m})$ & Depth $(\mathrm{cm})$ & Elevation $(\mathrm{m})$ & Depth $(\mathrm{cm})$ \\
\hline $1998.0 \sim 2005.5$ & $0 \sim 18$ & $1993.0 \sim 2005.5$ & $0 \sim 24$ & $1997.3 \sim 2005.5$ & $0 \sim 24$ \\
\hline
\end{tabular}

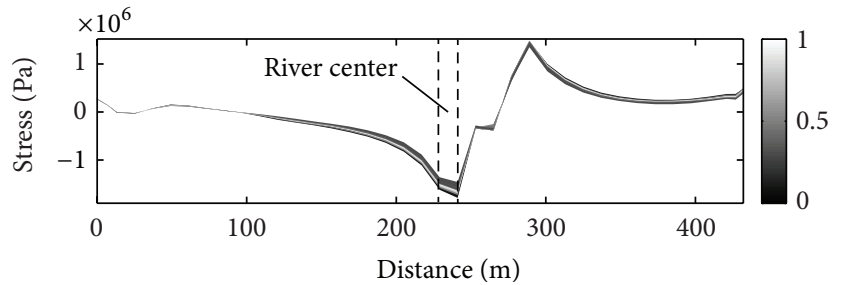

FIGURE 11: Contour plot of the membership function of stress $\sigma_{G}+$ $\sigma_{W}$ (in dam axis direction) of face slab surface at the elevation $2003.0 \mathrm{~m}$.

Since most observed cracks are above the water level (elevation: $2002.0 \mathrm{~m}$ ), in the following discussion, only the analysis results of some typical nodes of face slab FE mesh are shown. The location of these nodes is shown in Figure 10. Most observed cracks are parallel to the dam axis, so the only stress in dam axis direction is analyzed in the following. Define the positive stress as tensile stress and the negative stress as compressive stress.

The stress (in dam axis direction) caused by dam gravity and water pressure $\sigma_{G}+\sigma_{W}$ of face slab surface at the elevation $2003.0 \mathrm{~m}$ is shown in Figure 11. The $x$-axis of this figure refers to the distance from the first face slab of dam on the left side. It can be seen from the figure that the stress of face slabs near the river center is compressive, and the possible maximum compressive stress is about 1.4 million $\mathrm{Pa}$. Face slabs near the river bank are mainly subjected to tensile stress.

The calculated temperature of nodes A and B (see Figure 10) on face slab no. 5 is shown in Figure 12. It can be seen that the calculated temperature of face slab has similar trend with air temperature $T_{a}$, and the node, which is on the upper surface, is more susceptible to the influence of air temperature.

The contour plot of membership function of thermal stress (in dam axis direction) as a function of elevation of nodes on the line 1 (see Figure 10) is plotted in Figure 13.
The possibility distribution of stress of node $A$ and node $C$ is shown in Figure 14. The two figures show that the possible maximum tensile stress of face slab is about 2.7 million $\mathrm{Pa}$. The calculated tensile stress of Case 2 is obviously greater than that of Case 1 and so does the range of tensile stress exceeding the design value $\sigma_{y}=1.2$ million $\mathrm{Pa}$. For face slabs near riverbank, since the initial stress caused by dam gravity and water pressure is tensile (see Figure 11), the tensile stress caused by cold wave will make the total tensile stress of face slab larger. This is the very reason why most cracks found are on the face slabs near riverbank and face slabs near river center have little cracks; see Figure 4(a). For nodes below the water level (elevation: $2002.0 \mathrm{~m}$ ), we can see that the tensile stress decreases with the drop of elevation. This can illustrate that reservoir water plays a role of insulation material, which makes nodes below the water less affected by the outside temperature.

The direction of the maximum principle stress of nodes on the upper surface and the sketch of cracks of face slab no.5 are shown in Figure 15. It is obvious that the calculated cracking direction and the actual observed cracking direction are similar, and they are parallel to the dam axis.

The observed area with cracks and the calculated possible range (with a possibility great than 0 ) with tensile stress exceeding the design value $\sigma_{y}=1.2$ million $\mathrm{Pa}$ of face slab are shown in the Table 3 . We can see that the calculated cracking zone is similar with that of observed and the calculated cracking range of Case 2 is greater than that of Case 1. It means that the cold wave, which occurred in winter, has more impact on the cracking of face slab.

\section{Conclusion and Suggestion}

The analysis result using fuzzy FEM is more meaningful than that of using the traditional FEM, since the uncertainty of material parameters has been taken into account. For all the possible value of material parameters, the calculated face slab 


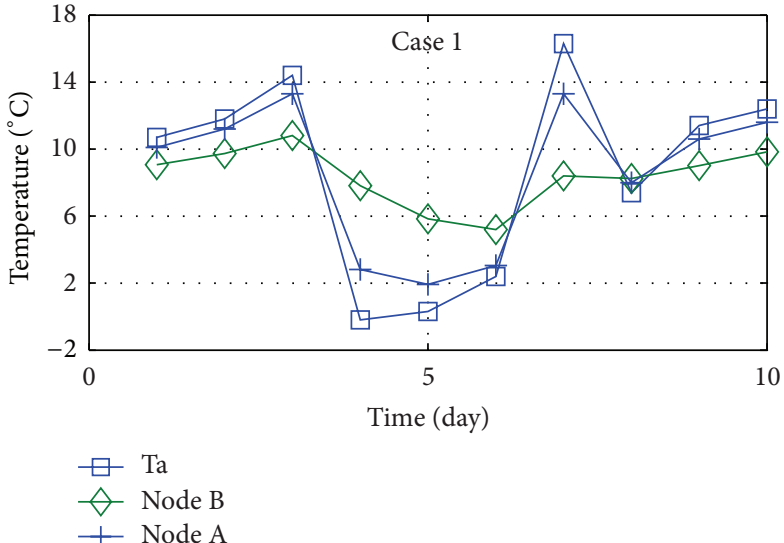

(a)

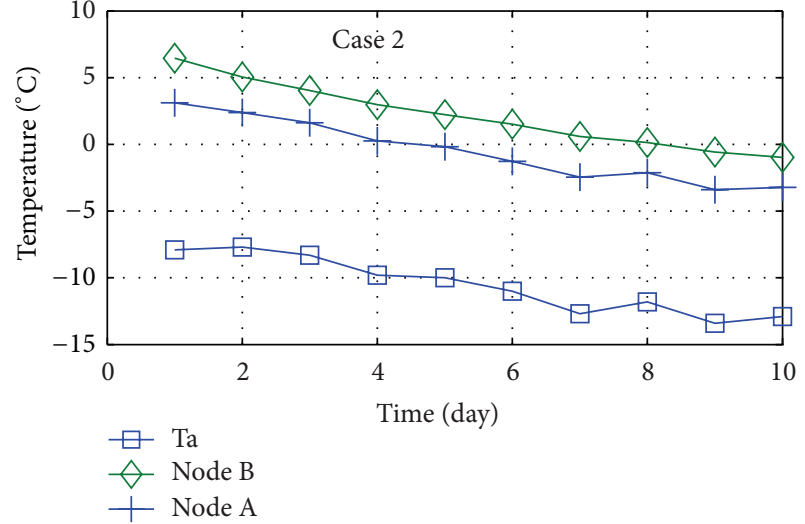

(b)

FIGURE 12: Calculated temperature of two nodes on face slab no. 5.

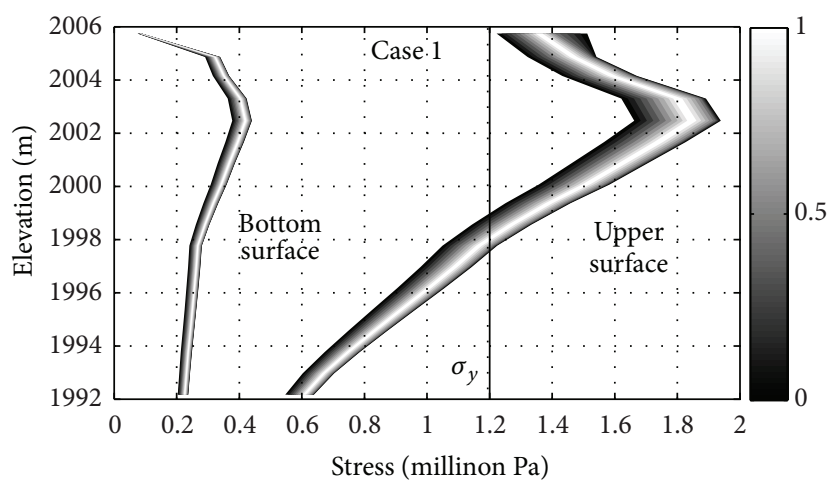

(a)

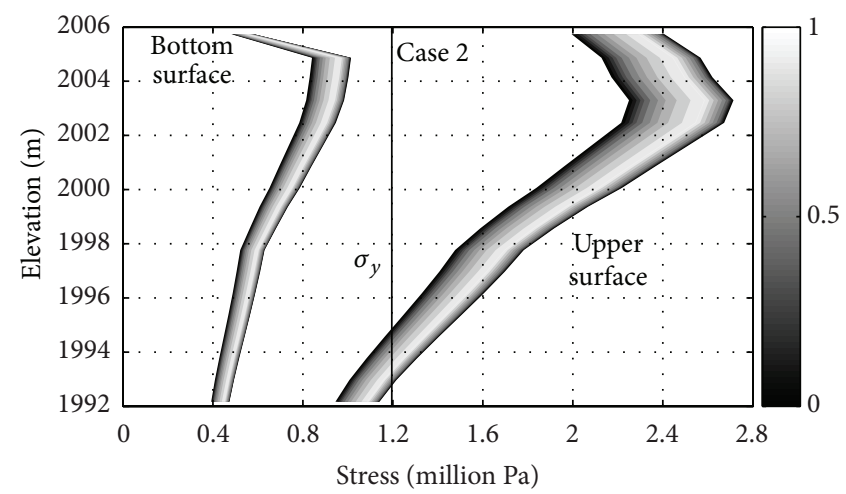

(b)

FIGURE 13: Contour plot of the membership function of thermal stress (in dam axis direction) as a function of the elevation.



(a)

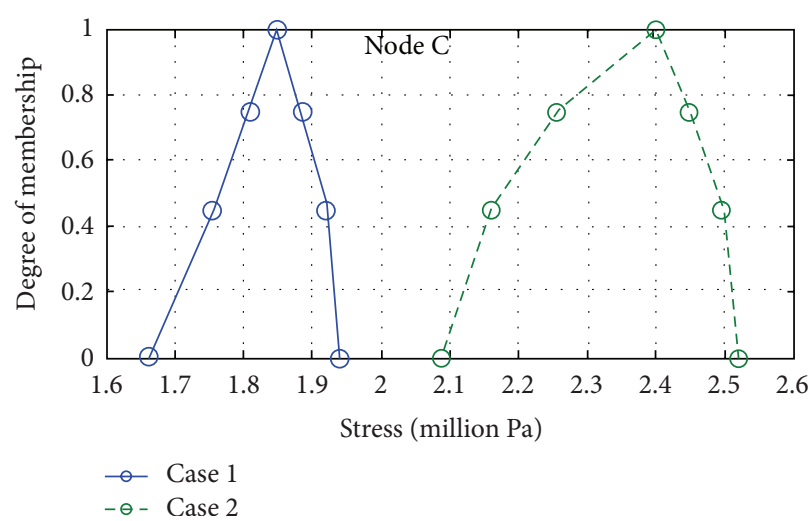

(b)

FIgURE 14: The membership function of stress (in dam axis direction) of node A and node C.

stress is within a certain range, which provides us with more information to evaluate the effect of cold wave on face slab cracking. Some conclusions of the above analysis are listed in the following.
(1) The calculated cracking direction and cracking zone are similar with that of observed. This means that the cold wave that caused swift air temperature drop is an important reason for the face slab cracking, although 


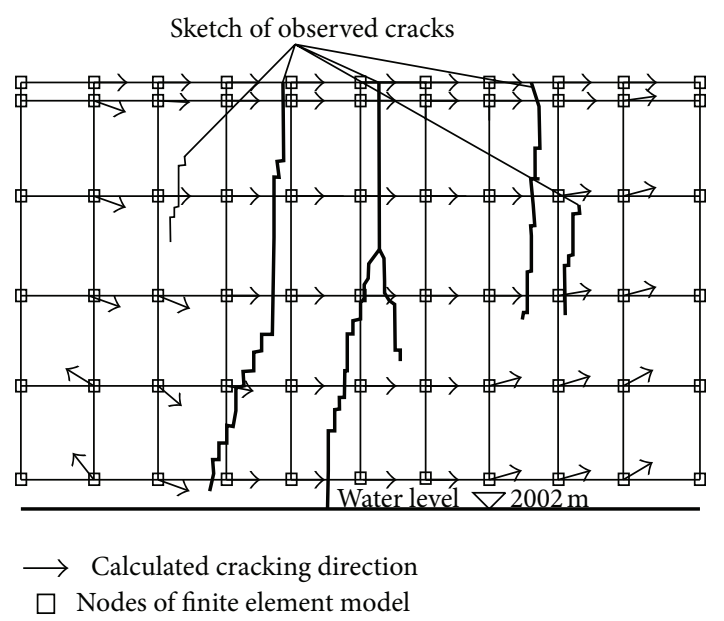

FigURE 15: Calculated and observed cracking direction of face slab no. 5 .

some other factors, such as creep, dry shrinkage of concrete, and uneven settlement of dam, cannot be directly ignored.

(2) In the two calculation cases, a special attention should be paid to the cold wave that occurred in winter, since the calculated result shows a greater influence of it on the face slab cracking.

Some of our suggestions to prevent the further cracking of face slab are as follows.

(1) For face slabs above the water level, it is necessary to take some insulation measures, such as covering the face slab with grass mat or plastic insulation material. This will prevent the slab from the effect of swift change of air temperature.

(2) As some cracks have extended to the elevation below the water level and some cracks have almost penetrated the face slab, it is necessary to adopt some engineering treatment measures such as chemical grouting to prevent the further extension of these cracks. Special attention should be paid to the monitoring data of dam seepage discharge. If the seepage discharge is abnormal, this may mean that water has infiltrated into the dam through face slab cracks.

\section{Acknowledgments}

This work was supported by the National Natural Science Foundation of China (Grants nos. 51279052 and 51139001), the Program for New Century Excellent Talents in University (Grant no. NCET-11-0628), the Special Fund of State Key Laboratory of China (Grant no. 2010585212), and the Ministry of Water Resources Public Welfare Industry Research Special Fund Project (Grant no. 201101013).

\section{References}

[1] K. T. Kavanagh and R. W. Clough, "Finite element applications in the characterization of elastic solids," International Journal of Solids and Structures, vol. 7, no. 1, pp. 11-23, 1971.

[2] S. S. Rao and J. P. Sawyer, "A fuzzy finite element approach for the analysis of imprecisely-defined systems," AIAA Journal, vol. 33, no. 12, pp. 2264-2370, 1995.

[3] B. M. Nicolaï, J. A. Egea, N. Scheerlinck, J. R. Banga, and A. K. Datta, "Fuzzy finite element analysis of heat conduction problems with uncertain parameters," Journal of Food Engineering, vol. 103, no. 1, pp. 38-46, 2011.

[4] T. M. Wasfy and A. K. Noor, "Application of fuzzy sets to transient analysis of space structures," Finite Elements in Analysis and Design, vol. 29, no. 3-4, pp. 153-171, 1998.

[5] J. C. Li, "Gohou dam and analysis for causes of the dam failure," Chinese Journal of Rock Mechanics and Engineering, vol. 16, no. 6, pp. 1-14, 1996.

[6] R. Wang, D. Wang, and Y. Chen, "Research on thermal stress of concrete slabs of rockfill dam under condition of cold wave attack," Journal of Hydroelectric Engineering, vol. 23, no. 6, pp. 45-49, 2004.

[7] W. Zhou, J. J. Hua, X. L. Chang, and Y. H. Cao, "Cause analysis of cracking of concrete slab for high CFRD based on concrete crushing-type side wall technology," Rock and Soil Mechanics, vol. 29, no. 8, pp. 2037-2041, 2008.

[8] Y. Arici, "Investigation of the cracking of CFRD face plates," Computers and Geotechnics, vol. 38, pp. 905-916, 2011.

[9] M. D. Yuan, M. Xiao, and G. H. Yang, "The 3D finite element analysis of cold wave impact effect," Procedia Engineering, vol. 31, pp. 791-800, 2012.

[10] M. E. Kartal, H. B. Başaĝa, and A. Bayraktar, "Probabilistic nonlinear analysis of CFR dams by MCS using response surface method," Applied Mathematical Modelling, vol. 35, no. 6, pp. 2752-2770, 2011.

[11] H. Su, J. Hu, and Z. Wen, "Structure analysis for concretefaced rock fill dams based on information entropy theory and finite element method," International Journal for Numerical and Analytical Methods in Geomechanics, vol. 36, pp. 1041-1055, 2012.

[12] U. O. Akpan, T. S. Koko, I. R. Orisamolu, and B. K. Gallant, "Practical fuzzy finite element analysis of structures," Finite Elements in Analysis and Design, vol. 38, no. 2, pp. 93-111, 2001.

[13] T. J. Ross, Fuzzy Logic With Engineering Applications, McGrawHill, New York, NY, USA, 1995.

[14] M. Hanss, "The transformation method for the simulation and analysis of systems with uncertain parameters," Fuzzy Sets and Systems, vol. 130, no. 3, pp. 277-289, 2002.

[15] H.-J. Bungartz and M. Griebel, "Sparse grids," Acta Numerica, vol. 13, pp. 147-269, 2004.

[16] D. Moens and M. Hanss, "Non-probabilistic finite element analysis for parametric uncertainty treatment in applied mechanics: recent advances," Finite Elements in Analysis and Design, vol. 47, no. 1, pp. 4-16, 2011.

[17] W. M. Dong and H. C. Shah, "Vertex method for computing functions of fuzzy variables," Fuzzy Sets and Systems, vol. 24, no. 1, pp. 65-78, 1987.

[18] Y. Z. Yu, B. Y. Zhang, and H. N. Yuan, "An intelligent displacement back-analysis method for earth-rockfill dams," Computers and Geotechnics, vol. 34, pp. 423-434, 2007. 
[19] D. Zheng, L. Cheng, T. Bao, and B. Lv, "Integrated parameter inversion analysis method of a CFRD based on multi-output support vector machines and the clonal selection algorithm," Computers and Geotechnics, vol. 47, pp. 68-77, 2013.

[20] D. G. Zou, H. F. You, X. J. Kong, and B. Xu, "Research on joint simplified model and effects of joint parameters on panel stress and joint displacements of faced rockfill dam," Chinese Journal of Rock Mechanics and Engineering, vol. 28, supplement 1, pp. 3257-3263, 2009.

[21] R. E. Goodman, R. L. Taylor, and T. L. Brekke, "A model for the mechanics of jointed rock," ASCE Journal of Soil Mechanic and Foundation, vol. 99, no. 3, pp. 637-660, 1968.

[22] B. Xu, D. G. Zou, and H. Liu, "Three-dimensional simulation of the construction process of the Zipingpu concrete face rockfill dam based on a generalized plasticity model," Computers and Geotechnics, vol. 43, pp. 143-154, 2012.

[23] J. M. Duncan and C. Y. Chang, "Nonlinear analysis of stress and strain in soils," ASCE Journal of Soil Mechanic and Foundation, vol. 96, no. 3, pp. 1629-1653, 1970.

[24] B. F. Zhu, Thermal Stress and Temperature Control of Massive Concrete, China Electric Power Press, Beijing, China, 1999.

[25] X. F. Zhang, S. Y. Li, and Y. L. Li, "Effect of superficial insulation on roller-compacted concrete dams in cold regions," Advance in Engineering Software, vol. 42, no. 11, pp. 939-943, 2011.

[26] MSC. Software Corporation, "MSC. Marc Volume A, Theory and user information," Version 2005. 




Advances in

Operations Research

mansans

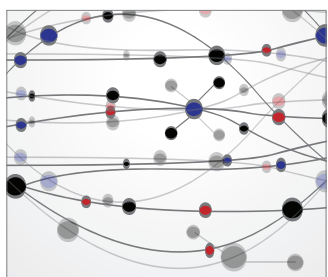

The Scientific World Journal
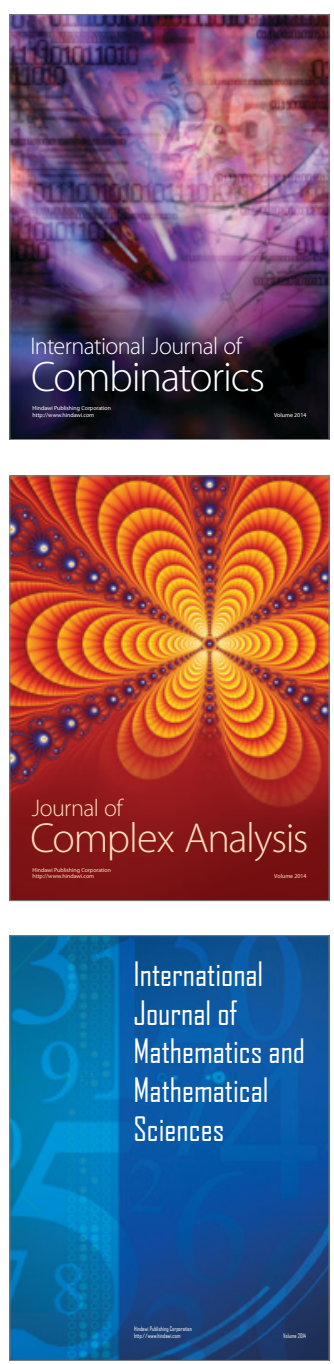
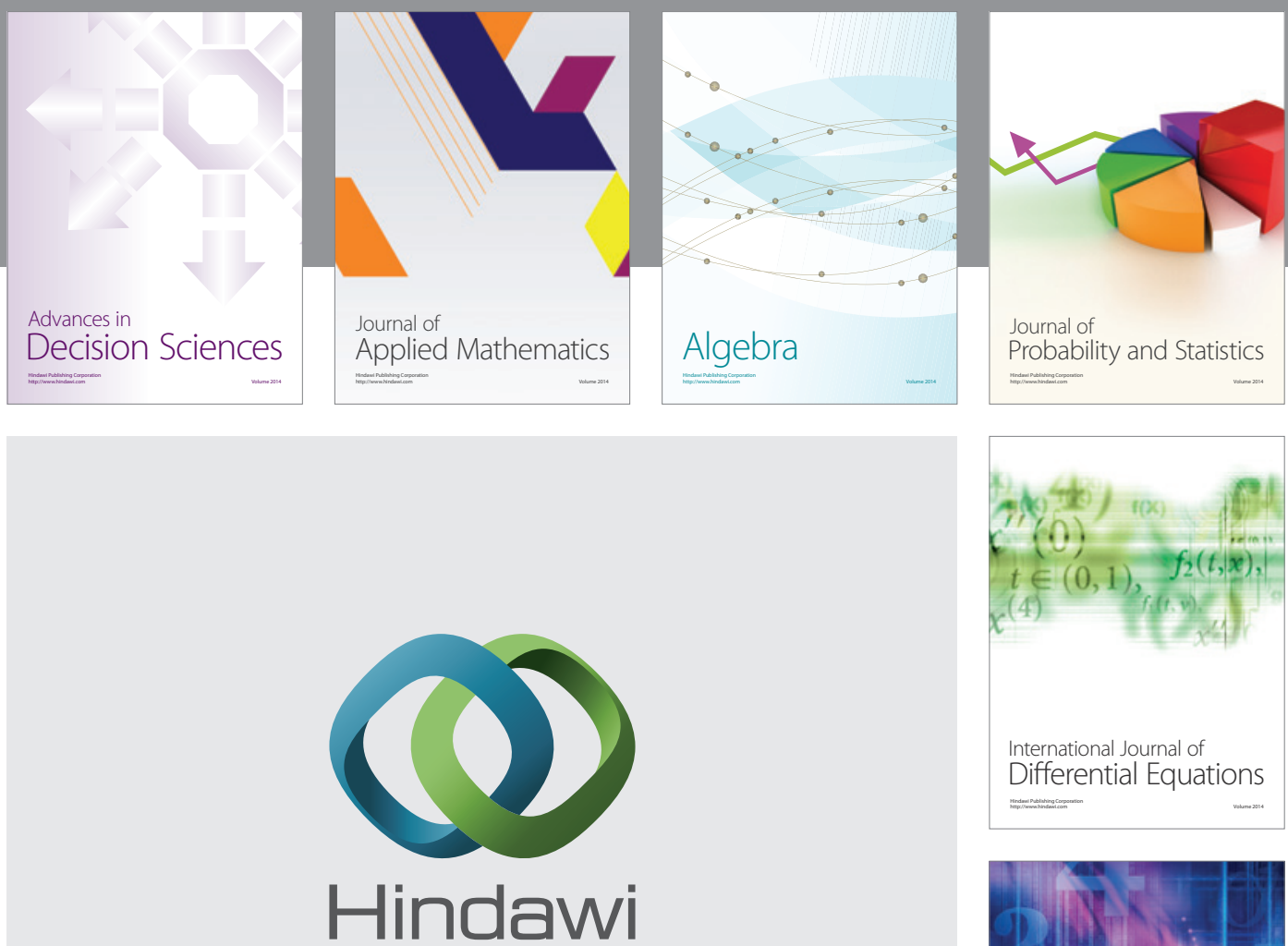

Submit your manuscripts at http://www.hindawi.com
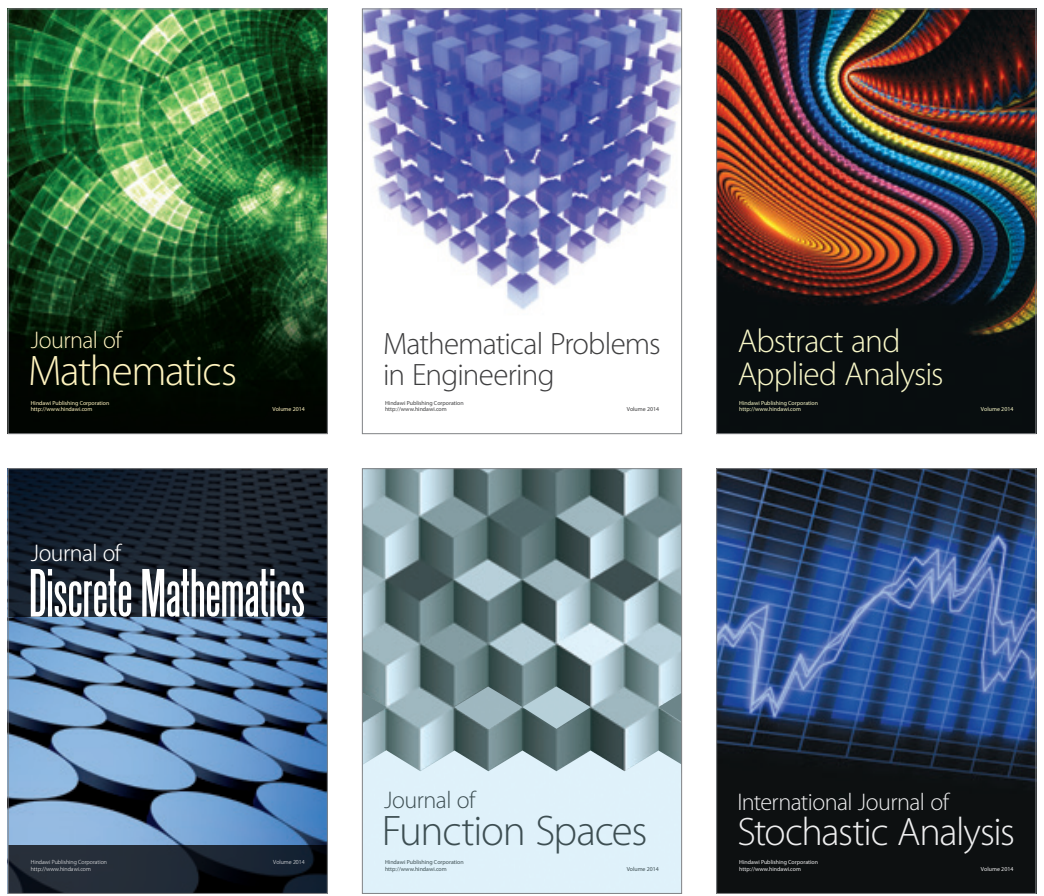

Journal of

Function Spaces

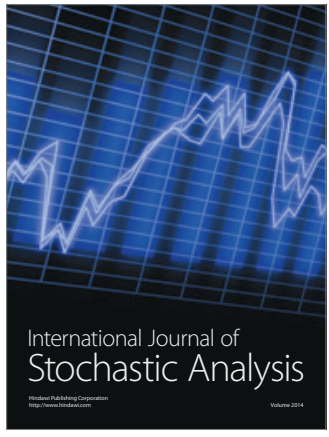

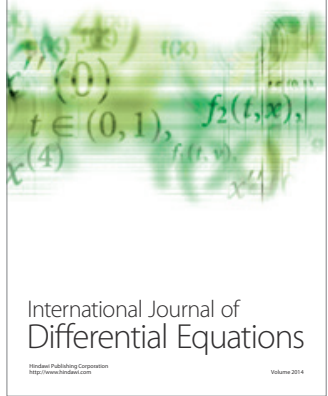
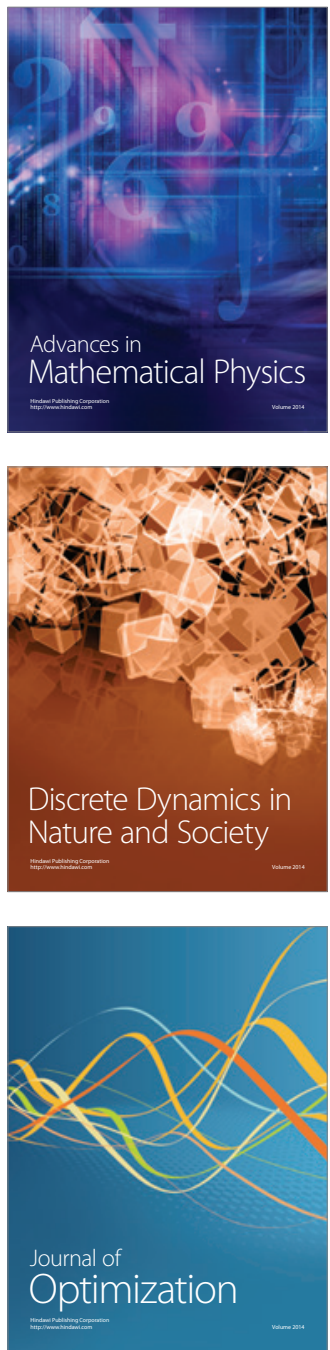